Res Nurs Health. 2008 February ; 31(1): 31-41. doi:10.1002/nur.20229.

\title{
Olfactory and Gustatory Sensory Changes to Tobacco Smoke in Pregnant Smokers
}

\author{
Pamela K. Pletsch ${ }^{1, \dagger}$, Kathryn I. Pollak ${ }^{2, \ddagger}$, Bercedis L. Peterson ${ }^{3, \uparrow, ~ J e o n g o k ~ P a r k ~}{ }^{1, \#, ~ C h e r y l ~}$ \\ A. Oncken ${ }^{4, \$}$, Geeta K. Swamy ${ }^{5, \S}$, and Pauline Lyna ${ }^{2, \delta}$ \\ ${ }^{1}$ School of Nursing, University of North Carolina, Chapel Hill, NC \\ 2Duke Comprehensive Cancer Center, Cancer Prevention, Detection and Control Research \\ Program; Department of Community and Family Medicine, Duke University Medical Center, \\ Durham, NC \\ ${ }^{3}$ Department of Biostatistics and Informatics and Bioinformatics, Duke University Medical Center, \\ Durham, NC \\ ${ }^{4}$ Department of Medicine and Obstetrics and Gynecology, University of Connecticut School of \\ Medicine, Hartford, CT \\ ${ }^{5}$ Department of Obstetrics and Gynecology, Duke University Medical Center, Durham, NC
}

\begin{abstract}
Models of smoking behavior change include addiction, social, and behavioral concepts. The purpose of this study was to explore the prevalence of two biologic factors, olfactory and gustatory responses to tobacco smoke, as potentially powerful contributors to smoking behavior change among pregnant women. Data were obtained from 209 pregnant smokers. The majority of women reported olfactory (62\%) and gustatory (53\%) aversions to tobacco. Aversions first appeared during the first trimester of pregnancy. Women who experienced olfactory aversions were more likely also to experience gustatory aversions. Olfactory aversions were associated with women smoking less. Aversions to tobacco smoke are common among pregnant smokers, are associated with women smoking less, and could help explain pregnant women's smoking patterns.
\end{abstract}

\section{Keywords}

tobacco; pregnancy; olfactory aversion; gustatory aversion

Cigarette smoking is a major preventable cause of cancer, cardiovascular disease, chronic obstructive pulmonary disease, reproductive dysfunction, and decreased bone density in women (Centers for Disease Control [CDC], 2005). Infants who live in households where smoking occurs are at an increased risk for sudden infant death syndrome and for a variety

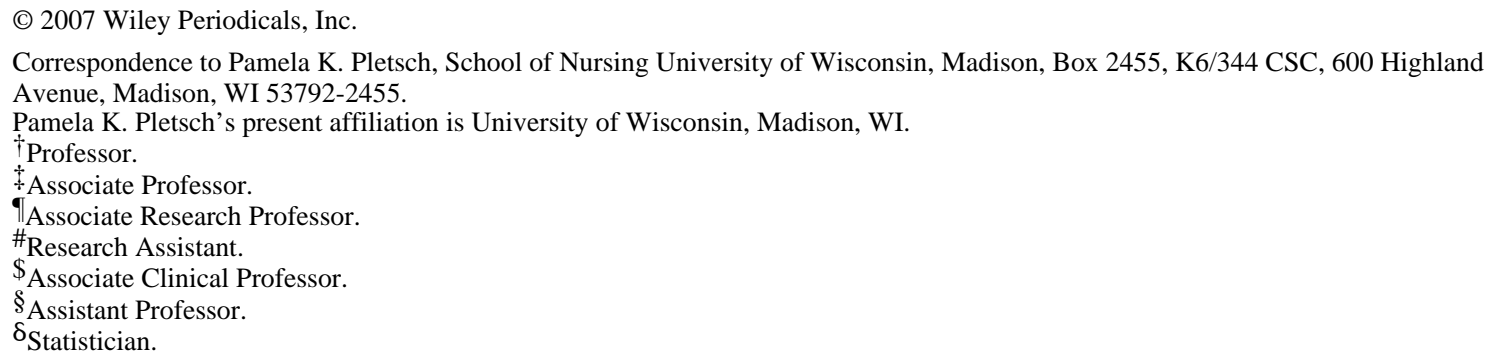


of respiratory problems, including asthma (Barber, Mussin, \& Taylor, 1996; Pollack, 2001). A substantial number of women change their smoking behavior while pregnant (Mathews \& Rivera, 2004), but the majority return to their usual smoking patterns after giving birth (Kahn, Certain, \& Whitaker, 2002; McBride et al., 1999). If women maintained their smoking abstinence after giving birth, many tobacco-related health problems for women and children could be prevented (Fagerstrom, 2002; Fiore et al., 2004). If smoking cessation during pregnancy became permanent for women, we would be closer to achieving the Healthy People 2010 target of reducing smoking among adults to $12 \%$ (U.S. Department of Health and Human Services, 2000). The purpose of this study was to describe the prevalence of pregnant women's sensory aversions to tobacco smoke. Currently, there are only anecdotal reports of pregnant women's tobacco aversions. If sensory aversions are widespread, they would be biologic factors that have the potential to provide a clearer explanation of the reasons women reduce smoking during pregnancy and resume postpartum.

The median smoking rate for women in the United States in 2004 was $19.2 \%$ with reported rates ranging from $9.4 \%$ to $26.4 \%$ (Kuiper, Malarcher, Bombard, Maurice, \& Jackson, 2005). Estimates of the percentage of women who smoke during pregnancy range from $10.5 \%$ to $17.1 \%$ (CDC, 2005). Although pregnancy is an opportune time for smoking cessation (McBride, Emmons, \& Lipkus, 2003), nearly 70\% of women in the United States who stop smoking during pregnancy resume by 12 months postpartum (DiClemente, DolanMullen, \& Windsor, 2000; Kahn et al., 2002; McBride et al., 1999). Despite the substantial amount of research on smoking behavior of pregnant and postpartum women, the high postpartum smoking resumption rates reveal our inadequate understanding of smoking behavior among this population of women.

In previous research women have reported a number of reasons for abstaining from smoking while pregnant (Ershoff, Quinn, \& Mullen, 1995; McBride et al., 1999; Secker-Walker, Solomon, Flynn, Skelly, \& Mead, 1998; Van't Hof, Wall, Dowler, \& Stark, 2000). One reason that has not been well-studied is women's sensory aversion to tobacco smoke during pregnancy (Cooksey, 1995; Tepper \& Seldner, 1999). Sipora, Murtaugh, Gregoire, and Duffy (2000) found that pregnant women had an increased sensitivity to various tastes and smells, yet the physiologic basis for these sensory changes during pregnancy is unclear. In several studies, there were anecdotal reports that women developed an aversion to tobacco smoke while pregnant (Duffy, Bartoshuk, Striegel-Moore,\&Rodin, 1998; Kolble, Hummel, von Mering, Huch, \& Huch, 2001; Prutkin et al., 2000). In a previous longitudinal qualitative study, we learned that women's aversion to tobacco smoke was a frequently reported reason for their abstaining from smoking while pregnant (Pletsch \& Kratz, 2004). After women gave birth, they reported that the aversion to tobacco smoke disappeared. Over $70 \%$ resumed smoking by 3 months postpartum (Pletsch \& Kratz). These findings suggest that sensory changes to tobacco smoke are important for understanding smoking abstinence and resumption among pregnant and postpartum women. To date, there has been no systematic quantitative investigation of the frequency with which pregnant smokers develop sensory aversions to tobacco.

Other factors related to smoking behavior during pregnancy and postpartum include dependence or addiction variables, pregnancy variables, social/interpersonal variables, and co-morbid health conditions. Dependence-related variables studied included: (a) the number of cigarettes smoked and the length of time women have smoked (Hajek et al., 2001; Ratner, Johnson, Bottorff, Dahinten, \& Hall, 2000), (b) women's readiness to stop smoking (Curry, McBride, Grothaus, Lando, \& Pirie, 2001; Klesges, Johnson, Ward, \& Barnard, 2001; Stotts, DiClemente, \& Dolan-Mullen, 2002); and (c) women's self-efficacy for smoking abstinence (Severson, Andrews, Lichtenshein, Wall, \& Akers, 1997; Van't Hof et al., 2000). Pregnancy 
variables studied included: (a) breast feeding plans (Ratner et al., 2000; Zimmer, 2000), and (b) women's concerns for the baby's health (McBride et al., 1999; Van't Hof et al.). Social/ interpersonal variables studied included: (a) partner or house-hold member smoking (Lelong, Kaminski, Saurel-Cubizolles, \& Bouview-Colle, 2001; McBride \& Pirie, 1990; Ratner et al.; Severson et al.; Van't Hof et al.), and (b) support for not smoking (Klesges et al., 2001; Pollak and Mullen, 1997; Van't Hof, et al.). Depression and other mental health problems are co-morbid health conditions that have been associated with smoking (Kahn et al., 2002). Smoking is a strategy used by many women to control their body weight, and many are concerned about the potential weight gain associated with smoking cessation (King, Matacin, Marcus, Bock, \& Tripolone, 2000; Levine, Perkins, \& Marcus, 2001).

Pregnancy presents a unique situation in which women are expected to gain weight for a healthy pregnancy, but most women hope to lose the extra weight after giving birth. Biological factors such as gustatory and olfactory sensory changes are absent from these lists. Because women experience substantial physiologic changes during pregnancy, exploration of the potential links between biology and behavior could provide us with a more complete understanding of women's smoking patterns.

The literature is inconsistent about the prevalence of gustatory and olfactory sensory changes during pregnancy, the nature of these changes, and the proposed biological mechanisms responsible for them (Lawson, LeMasers, \& Wilson, 2004; Swallow et al., 2005). Most of the research on gustatory and olfactory sensory changes during pregnancy has focused on changes in women's sensitivity to sweet, salty, sour, and bitter tastes and a variety of odors (Cooksey, 1995; Tepper \& Seldner, 1999). Study findings of the effect of pregnancy-related biochemical changes on women's taste and smell sensations have been mixed, but several investigators included anecdotal reports of women's aversion to tobacco smoke (Duffy et al., 1998; Kolble et al., 2001; Prutkin et al., 2000). Bartoshuk, Duffy, Reed, and Williams (1996) and Bartoshuk, Duffy, and Miller (1994) suggested that taste sensitivity in pregnant women is due to a high density of taste receptors on the anterior tongue. It has also been proposed that changes in taste sensitivity are due to fluctuations in sex hormones during pregnancy (Duffy et al.). Others proposed that changes are due primarily to nervous system anatomy; proximal regions of the brain are co-activated during phases of women's menstrual cycles and during pregnancy (Persinger, 2001). Although the mechanisms are unclear, there is speculation that the biochemical and hormonal changes that occur during pregnancy contribute to women's aversion to bitter tastes during the first trimester of pregnancy and are a biological mechanism to protect the embryo from poisons (Prutkin et al.).

Absent in the literature is a systematic investigation of the prevalence of pregnant women's tobacco-related sensory changes. Knowing if tobacco aversions are a typical experience for pregnant women could be useful in designing postpartum smoking resumption-prevention interventions. Interventionists could help women anticipate and plan for the loss of the aversions postpartum. The purpose of this study was to determine the prevalence of pregnant women's sensory changes to tobacco smoke, when the change first appeared, and if the presence of sensory changes was associated with changes in smoking behavior. The research questions were:

1. What percent of pregnant smokers experience gustatory or olfactory sensory changes to tobacco smoke and to foods?

2. For women who experienced a sensory change, when did the change first occur?

3. Were the sensory changes to tobacco smoke appealing or aversive? 
4. Is there an association between changes in olfactory and gustatory sensation changes to tobacco smoke?

5. Is there an association between sensory changes to tobacco smoke and smoking patterns?

\section{METHOD}

\section{Design and Procedures}

Data for this study were collected as part of the screening and baseline surveys of women who were being recruited for a large randomized trial of the effectiveness of pharmacologic therapy for smoking cessation among pregnant women. Recruitment procedures for this trial are reported in detail elsewhere (Pollak et al., 2006). Potential participants were recruited from 14 clinics in North Carolina that provide prenatal care. Most participants came from three clinics: two were affiliated with an academic medical center and the other with a large military installation. The remainder was smaller obstetrical and family practice clinics in the surrounding area. The study was approved by the Institutional Review Boards for the Protection of Human Subjects at each institution. All procedures were HIPAA compliant. Women were identified for study participation through medical record review following the first prenatal visit. Women with a history of smoking cigarettes were sent a letter informing them of the cessation trial and of procedures they should use if they did not want to be contacted about study participation. Those who did not decline were contacted by telephone by a professional survey company and were further screened for eligibility. Women who agreed to participate completed the baseline telephone survey questions that included the demographic and sensory data used in this study. The survey data were obtained prior to women being randomized to trial arms and prior to intervention participation. Thus the data represent the naturally occurring sensory changes and smoking behavior of study participants.

By the end of the third year of the trial, 434 pregnant women had been screened for eligibility for the cessation study, 328 responded to the screening questions on smoking, and of those, 239 women reported smoking cigarettes. Baseline data were collected by telephone surveys when women were between 12 and 20 weeks pregnant. At baseline 209 of the 239 $(88 \%)$ women were reached by telephone and responded to the survey questions (see Figure 1). All of the 209 pregnant women were at least 18 years old and reported smoking at least five cigarettes per day at baseline. A post-hoc power analysis revealed that with subgroup sizes of 59 and 99 (no sensory change/sensory change), the chi square test (2-sided a of .05) had $80 \%$ power to detect a $20 \%$ difference in subgroups' probability (.60 vs. .80) of women smoking less since becoming pregnant (Cohen, 1988).

\section{Sample}

The mean maternal age of the 209 participants was 26.4 ( $S D=5.6$ ); the majority were nonHispanic White (see Table 1). Most women were married or living with a partner. The majority had a high school education or less. A slight majority of women was unemployed. The current pregnancy was their first for $16 \%$ of the women. Women's report of their desire to quit smoking was quite high.

\section{Measures}

The demographic survey items had been developed and used in previous smoking cessation research by McBride et al. (2003). The sensory change questions were developed based on our earlier qualitative research on sensory changes during pregnancy (Pletsch \& Kratz, 2004) and included questions about tobacco smoke, food, and beverages. The questions 
were assessed for face validity by members of the cessation trial team who are experts in smoking and pregnancy. If women responded affirmatively to the sensory change questions, they were asked to describe the characteristics of the change and could select as many characteristics as applied to them. For example, in describing their responses to the smell of cigarette smoke, they could choose: made me feel sick (yes/no) and made me want to smoke more $(y e s / n o)$. Women were given the option to add other responses that were not on the prespecified list. Women were then asked how many weeks pregnant they were when they first noticed each olfactory or gustatory change (see Figure 2).

Smoking patterns since becoming pregnant were assessed at the initial survey screening. The smoking pattern questions had been developed by Mullen, Carbonari, Tabak, and Glenday (1991) and have been used to enhance disclosure of tobacco use by pregnant women. Mullen and colleagues studied 1,078 pregnant women and compared smoking disclosure using two formats. One was the multiple-option format we used in this study. The second was a dichotomous (yes/no) response to the question, "Do you smoke?" They found that the multiple-option format increased disclosure by $40 \%$. Their approach has been used in numerous studies and has been incorporated into the most recent tobacco clinical practice guideline (Fiore et al., 2000). Women who responded affirmatively to the first three questions in Figure 2 were eligible for participation in the cessation trial and were asked the sensory questions at the time of the baseline survey. For the data analysis, the first two questions were dichotomized and used as an indicator of change or no change in smoking behavior. Women who responded, "I smoke every once in a while" $(n=10)$ were not included in the analysis of change in smoking behavior because we could not determine if their answer reflected a change in smoking behavior (Table 2).

\section{Analysis}

Means, standard deviations, and percentages were used to describe the sample characteristics and the prevalence of sensory changes (research questions 1-3). Odds ratios were used to describe and test the association between gustatory and olfactory changes (research question 4). Separate logistic regression models were used to test the association of women's smoking behavior since becoming pregnant with gustatory changes and with olfactory changes (research question 5). Women's smoking behavior was measured as a dichotomous variable, with women reporting they either (a) smoked less or (b) smoked the same since becoming pregnant.

As an exploratory analysis, a third logistic regression model was used to test the association of smoking behavior and sensory changes with both gustatory and olfactory changes in the same model. In this model, we also controlled for two variables that have been associated with smoking cessation during pregnancy: (a) number of cigarettes smoked per day prior to pregnancy (smoking dependence) and (b) motivation to quit (a 7-level Likert-type scale). Because no previous quantitative analysis of gustatory and olfactory changes has been conducted, we chose a small number of covariates for this exploratory analysis. Odds ratios (smoking less divided by smoking the same) with $95 \%$ confidence intervals were used to describe the results of this regression model.

\section{RESULTS}

\section{Smoking Patterns}

At the initial screening for trial eligibility $(n=328), 46 \%$ of women reported that they smoked regularly, but had cut down since becoming pregnant. The next most frequent pattern was that women had quit smoking since becoming pregnant (22\%), followed by the category, smoked regularly, the same as before they were pregnant (16\%), and smoke every 
once in a while (11\%). A few women reported that they were not smoking when they became pregnant and were not currently smoking (5\%). For the sample of smokers for whom we have baseline sensory data $(n=209), 68 \%$ were smoking regularly, but had cut down; $26 \%$ were smoking the same; and $7 \%$ reported smoking every once in a while.

\section{Prevalence of Olfactory and Gustatory Sensory Changes}

Olfactory and gustatory sensory changes were common among this sample (see Table 2). Sensory changes were first noticed in the first trimester of pregnancy, and essentially all of the sensory changes to tobacco smoke were aversions. Sixty-three percent $(n=131)$ of women reported that cigarette smoke smelled different since they had become pregnant. Among these 131 women, the smell was characterized as, "smells worse" (39\%) and "makes me feel sick" (20\%). Only two women reported that cigarette smoke smelled better and that smelling cigarettes made them want to smoke more. The mean weeks of pregnancy when the olfactory change was first noticed was $7.3(S D=3.5)$. The prevalence of gustatory sensory changes to tobacco smoke was similar to olfactory sensory changes, with 53\% $(n=111)$ of the sample reporting that cigarettes tasted different. Among these 111 women, the change was characterized as, cigarettes "taste bad" (29\%), or "taste stronger" (26\%), with only $4 \%$ reporting that cigarettes tasted "more bitter." The mean weeks of pregnancy when women first noticed a change in the taste of cigarettes was $6.8(S D=3.1)$. To provide some context for the tobacco gustatory sensory changes, women were asked about gustatory changes to foods and beverages. Forty-seven percent $(n=97)$ of the sample reported gustatory changes to a wide variety of foods, and $42 \%(n=88)$ reported sensory changes to beverages. There were no consistent patterns to these changes, which included both aversions and cravings. The mean weeks of pregnancy when women first noticed the gustatory sensory changes to food was similar to that of the gustatory changes to cigarettes $(M=6.8, S D=2.8)$.

\section{Association Between Olfactory and Gustatory Sensory Changes}

There was a statistically significant association between women reporting an olfactory change (yes/no) and reporting a gustatory change (yes/no) to tobacco smoke $(n=208)$. Among the 78 women who reported no olfactory change, $42 \%$ reported a gustatory change. Among the 130 women with an olfactory change, $60 \%$ reported a gustatory change ( $O R=$ $2.04,95 \% C I=1.15-3.62, p=.01)$.

\section{Association Between Sensory Changes and Smoking Behavior}

There was a statistically significant association between an olfactory sensory change to tobacco smoke and women changing their smoking behavior. Among the 59 women who did not report an olfactory change, $63 \%$ reported that they were smoking less since becoming pregnant. Among the 99 women with an olfactory change, $78 \%$ reported that they were smoking less $(O R=2.08,95 \% C I=1.02-4.23, p=.04)$. On the other hand, there was no association between gustatory sensory changes and changes in smoking behavior. Among women with and without a gustatory change, $71.6 \%$ and $72.3 \%$ respectively reported smoking less since becoming pregnant $(O R=1.04,95 \% C I=.5,2.08, p=.94)$.

These unadjusted odds ratios were only slightly different from adjusted odds ratios calculated in the third logistic regression model that contained both gustatory and olfactory changes and two covariates. Specifically, when controlling for the number of cigarettes smoked prior to pregnancy $(p=.02)$ and desire to quit $(p=.97)$, the adjusted gustatory odds ratio was $1.01(95 \% C I=.48-2.11, p=.99)$, which is almost identical to the unadjusted odds ratio of 1.04. The adjusted olfactory odds ratio was 1.91 (95\% $C I=.91-3.98, p=.09$ ) which is just slightly less than the unadjusted odds ratio of 2.08. A post-hoc power analysis revealed that with the subgroup sizes in our sample (59 with no olfactory change and 99 with an olfactory change), the chi square test (2-sided a of .05) had only $52 \%$ power to 
detect a $15 \%$ difference in the proportion of women who smoked less versus smoked the same. The interaction between gustatory and olfactory changes in the prediction of smoking behavior was not significant and therefore was excluded from the final analysis.

\section{DISCUSSION}

This study addressed the perplexing problem of pregnant women's cigarette smoking behavior and contributes to research focused on addiction, interpersonal, social, and behavioral variables. Our aim was to explore potential biological influences on pregnant women's smoking by describing the prevalence of pregnant smokers' aversions to cigarette smoke and the relationships among aversions and smoking behavior. Our findings suggest that tobacco smoke sensory aversions occur in substantial numbers of pregnant smokers and that olfactory aversions potentially play a role in pregnant women smoking less. The sensory aversions first appeared in the first trimester of pregnancy.

This is the first known published study of the prevalence of both olfactory and gustatory sensory aversions to tobacco smoke among pregnant smokers. Although both aversions were common, it was surprising that only an olfactory aversion was associated with women smoking less since becoming pregnant. After controlling for covariates, the association between the olfactory aversion and the proportion of women smoking less remained substantial, but not statistically significant ( $p=.09$ for a $15 \%$ difference). Women in this study were quite homogeneous in their desire to quit smoking. The mean desire to quit score was high, there was modest variability, and all women were interested in the cessation trial. For this sample of women, all of whom wanted to quit, the observed $15 \%$ difference in smoking reduction among women with/without an olfactory aversion is clinically interesting and warrants further study.

Our findings should be generalized with caution. The design was cross sectional with data based on self-report. Participants were smoking at the time of data collection, changes in their smoking patterns were self-imposed, and all were interested in quitting. Although participants were living in North Carolina, the sample was diverse in terms of race and ethnicity, income, and education. There is no apparent reason that women in our sample were different from other pregnant smokers in their experience of sensory aversions.

One reason for conducting this study was to determine if aversions to tobacco were common enough to warrant further investigation, therefore a conceptual framework was not developed a priori. However, the sensory experiences described here and in our previous study (Pletsch \& Kratz, 2004) subsequently were used in the development of a risk assessment and intervention model for preventing women's return to smoking after giving birth (Pletsch, 2006). Our model is based on one developed by Abrams et al. (1996) and the intent is to tailor smoking counseling to patient characteristics. The model includes: assessment, development of a risk profile, triaging women to different levels of intervention intensity, and tailoring the timing and content of the intervention to women's risk profiles (Pletsch, 2006). The assessment portion of the model includes the dimensions of biobehavioral, co-condition, and pregnancy-specific smoking risks (see Figure 3). Changes in women's sensory response to tobacco smoke was included in the pregnancy-specific dimension of the model based on the findings from this study.

Our findings from this study, that sensory aversions are common and potentially are a reason women change their smoking behavior while pregnant, added an important component to our model for tailoring our smoking resumption-prevention intervention. Women who reduce or stop smoking because cigarette smoke has become aversive are at risk to resume smoking shortly after giving birth when the aversion disappears. Thus, the timing of the 
intervention counseling may need to be based on whether or not women experienced an olfactory aversion.

Our findings also suggest several avenues for future research. Further specification of tobacco smoke sensory aversions and potential relationships between tobacco aversions and nausea and vomiting of pregnancy (NVP) could reveal biological processes that are important for understanding smoking behavior.

The tobacco aversion descriptions in our sample are consistent with those of Kolble et al. (2001), who studied gustatory and olfactory sensitivity in 53 pregnant and 59 non-pregnant women. They found that pregnant women had more difficulty identifying bitter tastes than non-pregnant women and that pregnant women compared to non-pregnant women found the odors of cigarettes, rum, and coffee to be aversive. In our sample only a small number of women described tobacco smoke as tasting "more bitter," but the majority reported that tobacco smoke was aversive. Kolble and colleagues speculated that a decreased sensitivity to bitter tastes allows pregnant women to eat a wider variety of foods and that aversions to cigarettes, rum, and coffee protects the fetus from exposure to potentially harmful chemicals. However, Swallow et al. (2005) found no differences in olfactory sensitivity between pregnant women, non-pregnant women, and men. Cannon et al. (2005) studied the relationship between phenotypic sensitivity to bitter tastes, genotypes, and taste as a motivator for smoking. They found that people with an intermediate sensitivity to bitter taste were less likely to be smokers, but the genetic polymorphisms associated with taste sensitivity were unclear. The underlying genetic and hormonal mechanisms of sensory changes to tobacco are just beginning to be understood.

A second important finding was the association between women's olfactory aversion to tobacco smoke and their smoking less since becoming pregnant. Causation cannot be inferred from this association. However, in our earlier qualitative study women identified sensory aversions as a reason they had stopped smoking. Prospective studies would help us understand the relationships among pregnant women's sensitivity to bitter tastes, their aversion to the taste and smell of tobacco smoke and their smoking behavior. In our study we did not include women who had quit smoking. One could speculate that aversions were even more common among the women who quit. Future researchers should include spontaneous quitters because the strongest relationship between olfactory and gustatory changes and smoking behavior could occur in this group.

A third area of inquiry suggested by our findings is the relationship between tobacco smoke aversions and NVP. The onset of sensory aversions to tobacco smoke and food aversions and cravings occurred during the first trimester of pregnancy, when NVP typically occurs. McLeod, Pullon, and Cookson (2003) surveyed 829 pregnant women in New Zealand about their experiences with NVP. Among women who reported smoking at conception, $34 \%$ who experienced NVP stopped smoking during the first trimester compared to only $16 \%$ of women without NVP. However, Kallen, Lundberg, and Aberg (2003) studied 4,041 pregnant Swedish women and did not find a significant impact of NVP on smoking. Among prenatal smokers, $50 \%$ of those with NVP compared to $43 \%$ of those without NVP had stopped smoking by their first prenatal visit $(p=.07)$. It is unclear if NVP is the reason women stop smoking or if it is the physiologic changes that cause NVP that also make tobacco smoke aversive. As with the sensory changes discussed above, the causative mechanisms for NVP are unclear. Human chorionic gonadotropic, estrogen (ACOG Practice Bulletin, 2004) and prolactin and estradiol (Lagiou et al., 2003) have been postulated as causative agents, but the etiology is unknown. Longitudinal prospective research in which patterns of sensory aversions, NPV, reproductive hormones, and smoking behavior are studied would be useful for determining how sensory aversions to tobacco smoke during 
pregnancy fit into our conceptualizations of smoking behavior among pregnant and postpartum women. Investigating the potential linkages between NVP and tobacco aversion could provide clues to the biology of NVP and suggest potential biological approaches to preventing postpartum smoking resumption among women.

Our findings suggest multiple avenues for further exploration of pregnant women's sensory aversions to tobacco smoke. In the short-term, we are including sensory aversions as an assessment dimension to tailor a resumption-prevention intervention. Future research aimed at unraveling the causative mechanisms will lead to a better understanding of the links between genetics, biology, and behavior.

\section{Acknowledgments}

Contract grant sponsor: National Cancer Institute, NIH; Contract grant number: R01, CA89053.

\section{REFERENCES}

Abrams DB, Orleans CT, Niaura RS, Goldstein MG, Prochaska JO, Velicer W. Integrating individual and public health perspectives for treatment of tobacco dependence under managed health care: A combined stepped-care and matching model. Annals of Behavioral Medicine. 1996; 18:290-304. [PubMed: 18425675]

ACOG Practice Bulletin. Clinical management guidelines for Obstetrician-Gynecologists. Washington, DC: American College of Obstetricians and Gynecologists; 2004.

Barber K, Mussin E, Taylor DK. Fetal exposure to involuntary maternal smoking and childhood respiratory disease. Annals of Allergy, Asthma, and Immunology. 1996; 76:427-430.

Bartoshuk LM, Duffy VB, Miller IJ. PTC/PROP tasting: Anatomy, psychophysics, and sex effects. Physiology of Behavior. 1994; 56:1165-1171.

Bartoshuk LM, Duffy VB, Reed D, Williams A. Supertasting, earaches and head injury: Genetics and pathology alter our taste worlds. Neuroscience \& Biobehavioral Reviews. 1996; 20:79-87. [PubMed: 8622833]

Cannon DS, Baker TB, Piper ME, Scholand MB, Lawerence DL, Drayna DT, et al. Associations between phenylthiocarbamide gene polymorphisms and cigarette smoking. Nicotine \& Tobacco Research. 2005; 7:853-858. [PubMed: 16298720]

Centers for Disease Control Office on Smoking and Health. Women and smoking: A report of the Surgeon General 2001. 2005. Retrieved February 20, 2006 from http://www.cdc.gov/tobacco/sgr/ srg_forwomen/factsheet_tobaccouse.htm.

Cohen, J. Statistical power analysis for the behavioral sciences. 2nd ed.. Hillsdale, NJ: Lawrence Erlbaum; 1988.

Cooksey NR. Pica and olfactory craving of pregnancy: Howdeep are the secrets? Birth. 1995; 22:129_ 137. [PubMed: 7575860]

Curry SJ, McBride C, Grothaus L, Lando H, Pirie P. Motivation for smoking cessation among pregnant women. Psychology of Addictive Behavior. 2001; 15:126-132.

DiClemente CC, Dolan-Mullen P, Windsor RA. The process of pregnancy smoking cessation: Implications for interventions. Tobacco Control. 2000; 9:16-21. [PubMed: 10691754]

Duffy VB, Bartoshuk LM, Striegel-Moore R, Rodin J. Taste changes across pregnancy. Annals of the New York Academy of Sciences. 1998; 855:805-809. [PubMed: 9929689]

Ershoff DH, Quinn VP, Mullen PD. Relapse prevention among women who stop smoking early in pregnancy: A randomized clinical trial of a self-help intervention. American Journal of Preventive Medicine. 1995; 11:178-184. [PubMed: 7662397]

Fagerstrom K. The epidemiology of smoking: Health consequences and benefits of cessation. Drugs. 2002; 62:1-9. [PubMed: 12109931]

Fiore, MC.; Bailey, WC.; Cohen, SJ.; Dorfman, SF.; Goldstein, MG.; Gritz, ER., et al. Treating tobacco use and dependence: Clinical practice guideline. Washington, D.C.: U.S. Department of Health and Human Services. Public Health Service; 2000. 
Fiore MC, Croyle RT, Curry SJ, Cutler CM, Davis RM, Gordon C, et al. Preventing 3 million premature deaths and helping 5 million smokers quit: A national action plan for tobacco cessation. American Journal of Public Health. 2004; 94:205-210. [PubMed: 14759928]

Hajek P, West R, Lee A, Foulds J, Owen L, Eiser JR, et al. Randomized controlled trial of a midwifedelivered brief smoking cessation intervention in pregnancy. Addiction. 2001; 96:485-494. [PubMed: 11255587]

Kahn RS, Certain L, Whitaker RC. A reexamination of smoking before, during, and after pregnancy. American Journal of Public Health. 2002; 92:1801-1808. [PubMed: 12406812]

Kallen B, Lundberg G, Aberg A. Relationship between vitamin, use, smoking, and nausea and vomiting of pregnancy. Acta Obstetrics and Gynecology of Scandinavia. 2003; 82:916-920.

King TK, Matacin M, Marcus BH, Bock BC, Tripolone J. Body image evaluations in women smokers. Addictive Behavior. 2000; 25:613-618.

Klesges LM, Johnson KC, Ward KD, Barnard M. Smoking cessation in pregnant women. Obstetrics and Gynecology Clinics of North America. 2001; 28:269-282. [PubMed: 11430176]

Kolble N, Hummel T, von Mering R, Huch A, Huch R. Gustatory and olfactory function in the first trimester of pregnancy. European Journal of Obstetrics, Gynecology, and Reproductive Biology. 2001; 99:179-183.

Kuiper N, Malarcher A, Bombard J, Maurice E, Jackson K. State-specific prevalence of cigarette smoking and quitting among adults-United States, 2004. Morbidity and Mortality Weekly Report. 2005; 54:1124-1127. [PubMed: 16280970]

Lagiou P, Tamimi R, Mucci LA, Trichopoulos D, Adami HO, Hsieh CC. Nausea and vomiting in pregnancy in relation to prolactin, estrogens, and progesterone: A prospective study. Obstetrics and Gynecology. 2003; 1101:639-644. [PubMed: 12681864]

Lawson CC, LeMasters GK, Wilson KA. Changes in caffeine consumption as a signal of pregnancy. Reproductive Toxicology. 2004; 18:625-633. [PubMed: 15219624]

Levine MD, Perkins KA, Marcus MD. The characteristics of women smokers concerned about post cessation weight gain. Addictive Behavior. 2001; 26:749-756.

Lelong N, Kaminski M, Saurel-Cubizolles MJ, Bouvier-Colle MH. Postpartum return to smoking among usual smokers who quit during pregnancy. European Journal of Public Health. 2001; 11:334-339. [PubMed: 11582616]

Mathews TJ, Rivera CC. Smoking during pregnancy-United States, 1990-2002. Morbidity Mortality Weekly Report. 2004; 53:911-915.

McBride CM, Curry SJ, Lando HA, Pirie PL, Grothaus LC, Nelson JC. Prevention of relapse inwomen who quit smoking during pregnancy. American Journal of Public Health. 1999; 89:706-711. [PubMed: 10224982]

McBride CM, Emmons KM, Lipkus IM. Understanding the potential of teachable moments: The case of smoking cessation. Health Education Research. 2003; 18:156-170. [PubMed: 12729175]

McBride CM, Pirie PL. Postpartum smoking relapse. Addictive Behaviors. 1990; 15:165-168. [PubMed: 2343790]

McLeod D, Pullon S, Cookson T. Factors that influence changes in smoking behaviour during pregnancy. New Zealand Medical Journal. 2003; 116:1-8.

Mullen PD, Carbonari JP, Tabak ER, Glenday MC. Improving disclosure of smoking by pregnant women. American Journal of Obstetrics and Gynecology. 1991; 165:409-413. [PubMed: 1872348]

Persinger MA. Shifting gustatory thresholds and food cravings during pregnancy as expanding uterineinduced steady potential shifts within the insula: An hypothesis. Perception \& Motor Skills. 2001; 92:50-52.

Pletsch PK. A model for postpartum smoking resumption prevention for women who stop smoking while pregnant. Journal of Obstetric, Gynecologic, and Neonatal Nursing. 2006; 35:215-222.

Pletsch PK, Kratz AT. Why do women stop smoking during pregnancy? Cigarettes taste and smell bad. Health Care for Women International. 2004; 25:671-679. [PubMed: 15487485]

Pollack HA. Sudden infant death syndrome, maternal smoking during pregnancy, and the costeffectiveness of smoking cessation intervention. American Journal of Public Health. 2001; 91:432-436. [PubMed: 11236409] 
Pollak KI, Mullen PD. An exploration of the effects of partner smoking, type of social support, and stress on postpartum smoking in married women who stopped smoking during pregnancy. Psychology of Addictive Behaviors. 1997; 11:182-189.

Pollak KI, Oncken CO, Lipkus IM, Peterson BL, Swamy GK, Pletsch PK, et al. Challenges and solutions for recruiting pregnant smokers into a nicotine replacement therapy trial. Nicotine \& Tobacco Research. 2006; 8:547-554. [PubMed: 16920652]

Prutkin J, Duffy VB, Etter L, Fast K, Gardner LA, Lucchina DJ, et al. Genetic variation and inferences about perceived taste intensity in mice and men. Physiology \& Behavior. 2000; 69:161-173. [PubMed: 10854927]

Ratner PA, Johnson JL, Bottorff JL, Dahinten S, Hall W. Twelve-month follow-up of a smoking relapse prevention intervention for postpartum women. Addictive Behaviors. 2000; 25:81-92. [PubMed: 10708321]

Secker-Walker RH, Solomon LJ, Flynn BS, Skelly JM, Mead PB. Smoking relapse prevention during pregnancy. A trial of coordinated advice from physicians and individual counseling. American Journal of Preventive Medicine. 1998; 15:25-31. [PubMed: 9651635]

Severson HH, Andrews JA, Lichtenstein E, Wall M, Akers L. Reducing maternal smoking and relapse: Long-term evaluation of a pediatric intervention. Preventive Medicine. 1997; 26:120-130. [PubMed: 9010907]

Sipiora ML, Murtaugh MA, Gregoire MB, Duffy VB. Bitter taste perception and severe vomiting in pregnancy. Physiology of Behavior. 2000; 69:259-267.

Stotts AL, DiClemente CC, Dolan-Mullen P. One-to-one: A motivational intervention for resistant pregnant smokers. Addictive Behaviors. 2002; 27:275-292. [PubMed: 11817768]

Swallow BL, Lindow SW, Aye M, Masson EA, Alasalvar C, Quantick P, et al. Smell perception during early pregnancy: No evidence of an adaptive mechanism. British Journal of Obstetrics and Gynaecology. 2005; 112:57-62. [PubMed: 15663398]

Tepper BJ, Seldner AC. Sweet taste and intake of sweet foods in normal pregnancy and pregnancy complicated by gestational diabetes mellitus. American Journal of Clinical Nutrition. 1999; 70:277-284. [PubMed: 10426706]

U.S. Department of Health and Human Services. Understanding and improving health and objectives for improving health. Washington, DC: U.S. Government Printing Office; 2000. Healthy people. 2010.

Van't Hof SM, Wall MA, Dowler DW, Stark MJ. Randomised controlled trial of a postpartum relapse prevention intervention. Tobacco Control. 2000; 9:III.64-III.66.

Zimmer BA. Smoking relapse during postpartum. Online Journal of Knowledge Synthesis in Nursing. 2000; 7:6. 


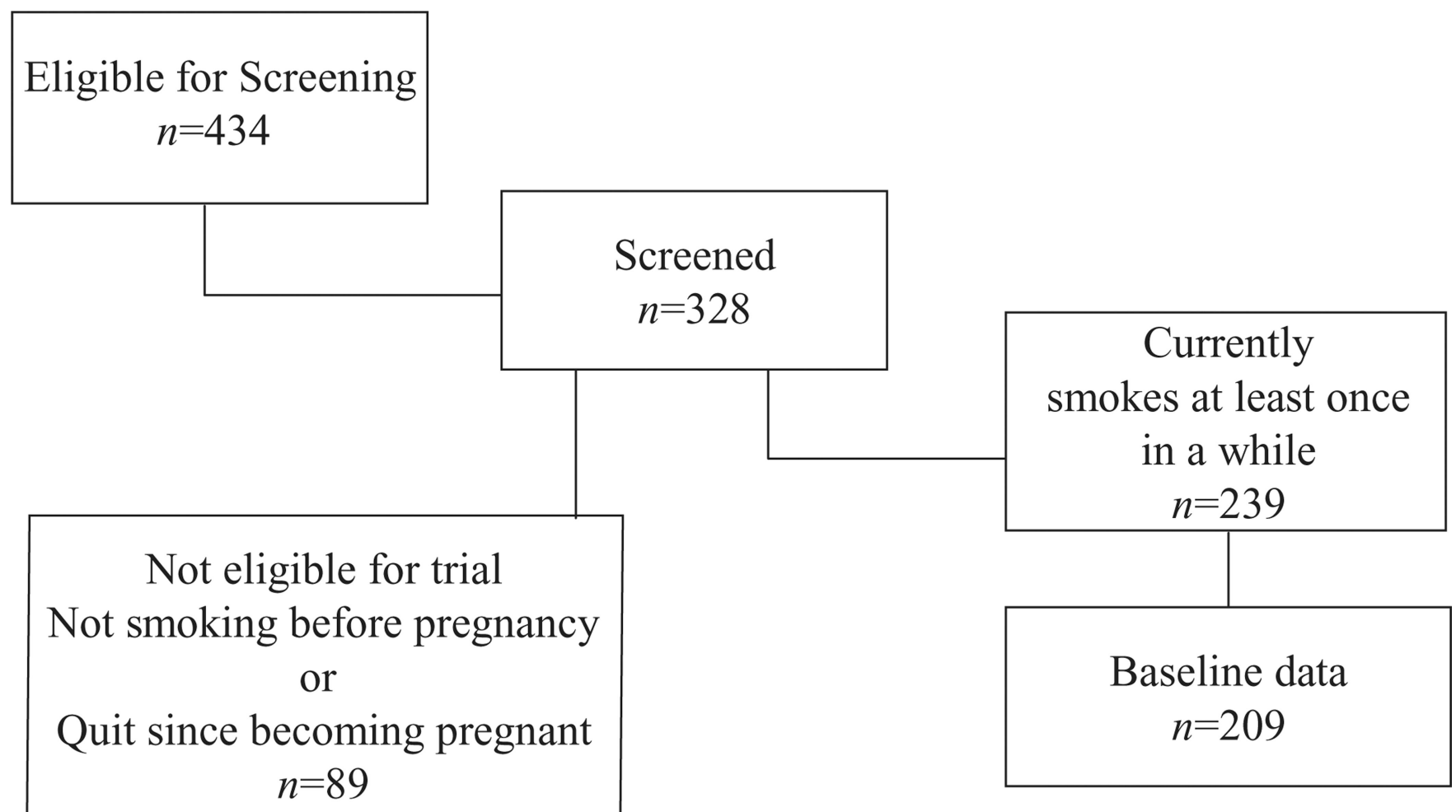

Figure 1.

Sample size. 
Smoking behavior change questions (Mullen, Carbonari, Tabak, \& Glenday, 1991):

In the past 7 days, would you say:

I smoke regularly now, about the same as before finding out I was pregnant. I smoke regularly now, but I've cut down since I found out I was pregnant.

I smoke every once in a while.

I have quit smoking since finding out I was pregnant.

I was not smoking around the time I found out I was pregnant.

I currently do not smoke cigarettes.

Figure 2.

Survey questions on smoking behavior changes. 
Risk Assessment

Dimensions

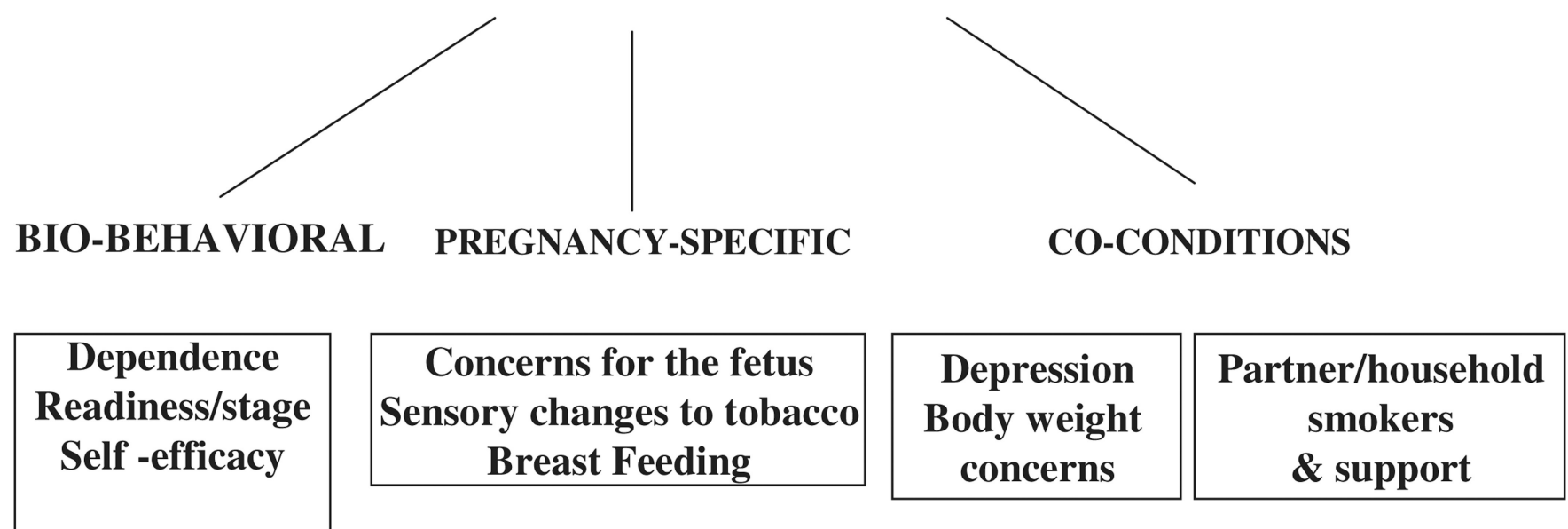

Figure 3.

Risk assessment for postpartum smoking resumption. 
Table 1

Participant Description $(\mathrm{n}=209)$

\begin{tabular}{|c|c|c|c|c|}
\hline Variable & $n$ & $M$ & & $S D$ \\
\hline Number of previous pregnancies & 208 & 2.3 & & 1.8 \\
\hline Cigarettes smoked per day in 30 days prior to pregnancy & 209 & 18.4 & & 8.1 \\
\hline \multirow[t]{2}{*}{ How much do you want to quit (scales $1-7$ ) } & 209 & 6.2 & & 1.2 \\
\hline & Frequency & & Percent & \\
\hline \multicolumn{5}{|l|}{ Education } \\
\hline Less than high school graduate & 60 & & 28.7 & \\
\hline GED or high school graduate & 77 & & 36.9 & \\
\hline Vocational, business school beyond high school, some college & 61 & & 29.2 & \\
\hline College graduate ( 4 years) & 10 & & 4.8 & \\
\hline Graduate education & 1 & & .5 & \\
\hline \multicolumn{5}{|l|}{ Marital status } \\
\hline Married, living with partner & 137 & & 65.6 & \\
\hline Single, never married & 55 & & 26.3 & \\
\hline Divorced/separated & 17 & & 8.1 & \\
\hline \multicolumn{5}{|l|}{ Race } \\
\hline White & 136 & & 65.1 & \\
\hline Black, African American & 55 & & 26.0 & \\
\hline Am Indian/Alaska native & 2 & & 1.0 & \\
\hline Pacific Islander/Asian & 3 & & 1.4 & \\
\hline Asian & 2 & & 1.0 & \\
\hline Other & 11 & & 5.3 & \\
\hline \multicolumn{5}{|l|}{ Latino/Hispanic ethnicity } \\
\hline Yes & 14 & & 6.7 & \\
\hline No & 195 & & 93.3 & \\
\hline \multicolumn{5}{|l|}{ Currently employed } \\
\hline Not employed & 115 & & 55.0 & \\
\hline Employed, full time & 64 & & 30.6 & \\
\hline Employed, part time & 29 & & 13.9 & \\
\hline Missing & 1 & & 0.5 & \\
\hline
\end{tabular}


Table 2

Prevalence of Olfactory and Gustatory Changes Since Becoming Pregnant $(n=209)$

\begin{tabular}{|c|c|c|}
\hline Variable & Frequency & Percent \\
\hline \multicolumn{3}{|l|}{ Foods taste different $(n=208)$} \\
\hline Yes & 97 & 46.6 \\
\hline No & 111 & 53.4 \\
\hline \multicolumn{3}{|l|}{ Beverages taste different $(n=209)$} \\
\hline Yes & 88 & 42.1 \\
\hline No & 121 & 58.0 \\
\hline \multicolumn{3}{|l|}{ Cigarettes taste different $(n=209)$} \\
\hline Yes & 111 & 53.1 \\
\hline No & 97 & 46.4 \\
\hline Don't know & 1 & .5 \\
\hline \multicolumn{3}{|l|}{ If yes, how has taste changed? } \\
\hline Tastes "bad" & 32 & 28.8 \\
\hline Tastes stronger & 29 & 26.1 \\
\hline Tastes more bitter & 4 & 3.6 \\
\hline \multicolumn{3}{|l|}{ Cigarettes smell different $(n=209)$} \\
\hline Yes & 131 & 62.3 \\
\hline No & 78 & 37.3 \\
\hline \multicolumn{3}{|l|}{ If yes, how has smell changed? } \\
\hline Smells "worse" & 51 & 38.9 \\
\hline Makes me feel sick & 26 & 19.9 \\
\hline Smells "better" & 2 & 1.5 \\
\hline Want smoke more & 2 & 1.5 \\
\hline \multicolumn{3}{|l|}{ Smoking behavior since becoming pregnant $(n=169)$} \\
\hline Smoke regularly, same as before & 44 & 26.0 \\
\hline Smoke regularly, cut down & 114 & 67.5 \\
\hline Smoke every once in a while & 11 & 6.5 \\
\hline Weeks of pregnancy when first noticed a change in the: & Mean & $S D$ \\
\hline Taste of cigarette smoke & 6.8 & 3.1 \\
\hline Smell of cigarette smoke & 7.3 & 3.5 \\
\hline Taste of foods & 6.8 & 2.8 \\
\hline
\end{tabular}

